University of Nebraska - Lincoln

DigitalCommons@University of Nebraska - Lincoln

Faculty Publications from the Center for Plant

Science Innovation

Plant Science Innovation, Center for

April 2004

\title{
Evaluation of the Escherichia coli threonine deaminase gene as a selectable marker for plant transformation
}

\author{
A. Ebmeier \\ University of Nebraska - Lincoln \\ L. Allison \\ University of Nebraska - Lincoln \\ Heriberto D. Cerutti \\ University of Nebraska - Lincoln, hcerutti1@unl.edu \\ Thomas E. Clemente \\ University of Nebraska - Lincoln, tclemente1@unl.edu
}

Follow this and additional works at: https://digitalcommons.unl.edu/plantscifacpub

Part of the Plant Sciences Commons

Ebmeier, A.; Allison, L.; Cerutti, Heriberto D.; and Clemente, Thomas E., "Evaluation of the Escherichia coli threonine deaminase gene as a selectable marker for plant transformation" (2004). Faculty Publications from the Center for Plant Science Innovation. 27.

https://digitalcommons.unl.edu/plantscifacpub/27

This Article is brought to you for free and open access by the Plant Science Innovation, Center for at DigitalCommons@University of Nebraska - Lincoln. It has been accepted for inclusion in Faculty Publications from the Center for Plant Science Innovation by an authorized administrator of DigitalCommons@University of Nebraska Lincoln. 
Published in Planta: An International Journal of Plant Biology 218 (2004), pp. 751-758; doi 10.1007/s00425-003-1129-x

Copyright (C) 2003 Springer-Verlag. Used by permission. http://www.springerlink.com/content/0032-0935

Submitted May 1, 2003; accepted September 27, 2003; published online December 12, 2003

\title{
Evaluation of the Escherichia coli threonine deaminase gene as a selectable marker for plant transformation
}

\author{
A. Ebmeier ${ }^{1}$, L. Allison ${ }^{2}$, H. Cerutti ${ }^{3,5}$, and T. Clemente ${ }^{1,4,5, *}$ \\ ${ }^{1}$ Department of Agronomy \& Horticulture, University of Nebraska-Lincoln, Lincoln, NE 68588-0665, USA \\ ${ }^{2}$ Department of Biochemistry, University of Nebraska-Lincoln, Lincoln, NE 68588-0665, USA \\ ${ }^{3}$ School of Biological Sciences, University of Nebraska-Lincoln, Lincoln, NE 68588-0665, USA \\ ${ }^{4}$ Center for Biotechnology, University of Nebraska-Lincoln, Lincoln, NE 68588-0665, USA \\ ${ }^{5}$ Plant Science Initiative, University of Nebraska-Lincoln, Lincoln, NE 68588-0665, USA \\ * Corresponding author: T. Clemente: email tclemente1@unl.edu ; fax 402 472-3139
}

\begin{abstract}
The initial step in the synthesis of isoleucine (Ile) is the conversion of threonine to $\alpha$-ketobutyrate. This reaction is carried out by threonine deaminase (TD), which is feedback-regulated by Ile. Mutations in TD that manifest insensitivity to Ile feedback inhibition result in intracellular accumulation of Ile. Previous reports have shown that in planta expression of the wild-type Escherichia coli TD, ilvA, or an Ile-insensitive mutant designated ilvA-466, increased cellular concentrations of Ile. A structural analog of Ile, L-O-methylthreonine (OMT), is able to compete effectively with Ile during translation and induce cell death. It has been postulated that OMT could therefore be utilized as an effective selective agent in plant engineering studies. To test this concept, we designed two binary plasmids that harbored an nptII cassette and either the wild-type ilvA or mutant ilvA-466. The ilvA coding sequences were fused to a plastid transit peptide down stream of a modified 35S CaMV promoter. Tobacco transformations were set up implementing a selection protocol based on either kanamycin or OMT. The ilvA gene was effectively utilized as a selectable marker gene to identify tobacco transformants when coupled with OMT as the selection agent. However, the transformation efficiency was substantially lower than that observed with nptII using kanamycin as the selection agent. Moreover, in a subset of the ilvA transformants and in a majority of the ilvA-466 transgenic lines, a severe off-type was observed under greenhouse conditions that correlated with increased levels of expression of the ilvA transgene.
\end{abstract}

Keywords: Agrobacterium, O-methyl threonine, threonine dehydratase

Abbreviations: ELISA - enzyme-linked immunosorbent assay; Ile - isoleucine; OMT - L-O-methylthreonine; nptII - neomycin phosphotransferase II; TD - threonine deaminase

\section{Introduction}

Gene transfer protocols for plant species require the use of visual or selectable marker genes to allow for efficient identification of the relatively small number of cells in which integration of the foreign DNA actually occurs. The choice of selectable marker gene and selective agent can significantly impact transformation efficiency making the search for improved selectable marker genes a continuing process.
The selectable marker genes neomycin phosphotransferase II (nptII; Fraley et al. 1983) and hygromycin phosphotransferase ( $h p t$; Waldron et al. 1985), which detoxify kanamycin and hygromycin respectively, have been widely adapted to a number of plant transformation protocols. A third antibiotic that has been used as a means to select transformed plants, although not as extensively as hygromycin or kanamycin, is methotrexate. The latter targets the enzyme dihydrofolate reductase ( $d h f r)$. A methotrexateinsensitive $d h f r$, encoded from a mutant mouse $d h f r$ gene, 
has been used as a selectable marker gene in plant genetic engineering studies (Eichholtz et al. 1987). A number of herbicide-resistance genes have also been implemented as selectable markers, including those for glyphosate tolerance, CP4 and GOX (Barry et al. 1992), the former being a glyphosate-tolerant 5-enolpyruvylshikimate-3-phosphate synthase (EPSP) synthase, the cellular target of glyphosate, and the latter capable of metabolizing glyphosate. The bar gene which degrades phosphinothricin, targeting glutamine synthase (De Block et al. 1987; Thompson et al. 1987) has also been used successfully in plant genetic engineering studies for a variety of plant species. The cynamamide hydratase gene (Cah), derived from the soil fungus Myrothecium verrucaria (Maier-Greiner et al. 1991), which imparts tolerance to the herbicidal activity of the nitrogen fertilizer calcium cyanamide via a degrading mode of action, has been used effectively for the identification of transgenic wheat plants (Weeks et al. 2000).

The Escherichia coli manA (phosphomannose isomerase) gene, also referred to as pmi, has been used as part of a positive selection scheme for the identification of transgenic plant tissue (Joersbo et al. 1999) coupled with medium supplemented with mannose. This system works via a detoxification mode, whereby mannose is converted to mannose6-phosphate, which cannot be metabolized further in plant cells and build-up of this metabolite is lethal. The pmi gene product will convert mannose-6-phosphate to fructose-6phosphate, which is non-toxic and can be utilized as a carbon source. This system has been shown to be very efficient in plant engineering studies (Negrotto et al. 2000).

Perturbing amino acid metabolism has been demonstrated as a means to identify transgenic plants (Perl et al. 1993). The first committed step in the aspartate regulatory pathway, which ultimately leads to the production of lysine, threonine, methionine and isoleucine (Ile), is the conversion of aspartate to 3-aspartylphosphate via the enzyme aspartate kinase (AK). Several isozymes of AK are known to be feedback inhibited by millimolar concentrations of lysine and threonine (Bryan 1980). Hence, incorporating threonine and lysine supplements in plant culture media will result in feedback inhibition of AK, which will manifest depletion of methionine, and thus cell death (Arruda et al. 1984). Mutations in AK, which result in feedback insensitivity to threonine and lysine, will permit tissue growth under culture conditions with the amino acid supplements (Rognes et al. 1983; Miao et al. 1988). Perl et al. (1993) were able to successfully utilize a threonine/lysine E. coli feedback-insensitive AK mutant as a selectable marker gene when coupled with a $2 \mathrm{mM}$ threonine/lysine supplement to the regeneration medium to recover transgenic potato lines.

One of the key enzymes downstream in the aspartatefamily biosynthetic pathway, involved in the first step in the biosynthesis of Ile, is threonine deaminase (TD). TD converts threonine to $\alpha$-ketobutyrate, and itself is feed- back-regulated by Ile. Inhibition of TD is herbicidal to plant cells, and the herbicidal activity of TD inhibition can be circumvented with supplements of $\alpha$-ketobutyrate and Ile itself (Szamosi et al. 1994), reflecting the depletion of Ile as the cause of cell death. An alternative approach to mimic Ile depravation is the use of a structural analog of the amino acid that can effectively compete during translation to induce cell death. One such example is O-methylthreonine (OMT; Rabinovitz et al. 1955). As part of a large mutant screen of Arabidopsis lines that were altered in biosynthesis of branched-chain amino acids, Mourad and King (1995) characterized a set of mutants resistant to OMT. The ability of these mutant lines to develop on OMT was attributed to a single nuclear gene, omr1, a mutant allele of TD, which mapped to chromosome 3. The OMT-tolerant Arabidopsis lines possessed substantially enhanced intracellular levels of Ile compared to wild-type plants. Moreover, there was a 50-fold increase in the Ile feedback insensitivity of TD activity in the OMT-tolerant lines compared to that in wild-type plants (Mourad and King 1995). These results lead the authors to speculate that the omr 1 allele of $A$. thaliana may serve as an effective plant selectable marker gene, coupled with OMT, for use in plant genetic engineering studies (Mourad and King 1995). Slater et al. (1999) introduced into A. thaliana and Brassica napus either the E. coli wild-type TD gene, ilvA, or a feedback-insensitive mutant ilvA-466. Transformants expressing either of these transgenes displayed elevated intracellular levels of Ile.

This study was undertaken to ascertain if the E. coli wild-type ilvA or the ilvA-466 derivative could be utilized as a selectable marker gene in plant genetic engineering studies when coupled with OMT as the selection agent, thus permitting a direct testing of the hypothesis put forth by Mourad and King (1995).

\section{Materials and methods}

Vector constructions

The open reading frames of Escherichia coli ilvA and the Ile feedback-insensitive mutant ilvA-466 (Slater et al. 1999) were fused to the transit peptide of the pea (Pisum sativum L.) small subunit of Rubisco. The resultant elements were subsequently subcloned down-stream of the TMV translational enhancer element, $\Omega$, under the control of a modified 35S CaMV promoter (Mitsuhara et al. 1996). The derived ilvA cassettes were cloned into the binary plasmid pPZP212 (Hajdukiewicz et al. 1994), and the resultant binary plasmids are referred to as pPTN272 (Figure 1a) and pPTN279 (Figure 1b), which carry the ilvA-466 and ilvA genes, respectively.

Tobacco transformations

The binary vectors pPTN272 and pPTN279 were mobilized into Agrobacterium tumefaciens strain $\mathrm{C} 58 \mathrm{C} 1$ harboring the disarmed $\mathrm{Ti}$ plasmid pMP90 (Koncz and Schell 1986) by tri-parental mating (Ditta et al. 1980). The resultant transconjugants were used in tobacco (Nicotiana tabacum L. cv. Xanthii) transformation studies implementing the 
Figure 1 Plant transformation vectors pPTN272 (left) and pPTN279 (right). $R B$ Right border element, $L B$ left border element, TPSS/Pea SSU transit peptide element from the pea (Pisum sativum) small subunit of Rubisco, Tnos $3^{\prime}$ termination element of the nopaline synthase gene, Term 3' termination element of the $35 \mathrm{~S} \mathrm{CaMV}$ transcript.
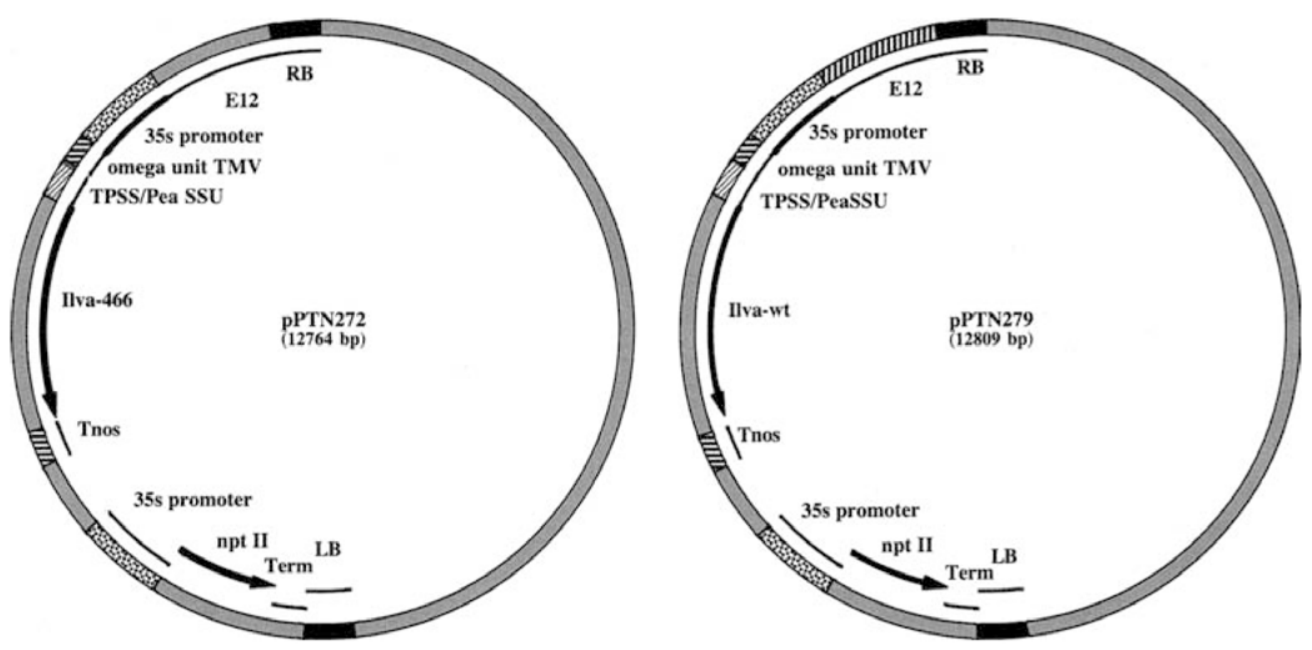

leaf-disc protocol described by Horsch et al. (1985). OMT levels ranging from $1.5 \mathrm{mg} \mathrm{l}^{-1}$ up to $12 \mathrm{mg} \mathrm{l}^{-1}$ were evaluated as a selection-pressure regime to identify transformants, while $150 \mathrm{mg}^{-1}$ kanamycin was used as a comparison in each of the transformation experiments. The OMT selection study consisted of five replications (plates) per treatment with five explants per replication. Each OMT selection pressure/plasmid treatment was evaluated 3-10 times. A minimum of 71 explants per selection regime was screened. Data were gathered on callus initiation after 2 weeks in culture, shoot differentiation following 4 weeks in culture, and the total number of rooted seedlings. A subset of rooted seedlings was established in soil. The $T_{0}$ and $T_{1}$ plants were further characterized for both TD expression and amino acid composition.

Protein expression analyses

TD and nptII expression levels within the tobacco transformants were monitored via western blot analysis and enzyme-linked immunosorbent assay (ELISA), respectively. For TD expression via western blot analysis, $50 \mathrm{mg}$ of plant tissue was collected and ground in $500 \mu \mathrm{l}$ of protein extraction buffer [ $25 \mathrm{mM}$ Tris (pH 8.0), 1 mM EDTA, 5 mM DTT]. The mixture was sonicated for approximately $20 \mathrm{~s}$ on ice and briefly vortexed. Protein concentrations were ascertained using Bio-Rad's proteinassay reagent (Cat \# 500-0006) following the manufacturer's protocol. Ten micrograms of protein was mixed with an equal volume of $2 \times$ sample buffer [125 mM Tris (pH 6.8), 4\% SDS, $10 \%$ glycerol, $0.006 \%$ bromophenol blue, $1.8 \% \beta$-mercaptoethanol]. The samples were subsequently boiled for $5 \mathrm{~min}$ and centrifuged at $14 \mathrm{~K}$ for $2 \mathrm{~min}$. The prepared protein samples were then separated on a $7.5 \%$ or $15 \%$ polyacrylamide resolving gel (Bio-Rad Cat \# 345-0005). The separated protein samples were electro-blotted to a nitrocellulose membrane for $1 \mathrm{~h}$ at $100 \mathrm{~V}$. Antiserum MR336 (kindly provided by Monsanto Company) derived from $E$. coli IlvA protein was used in 1:1,000 dilution in the primary incubation step in order to detect the expected 61-kDa protein. Protein detection was formed using Bio-Rad's ImmunoBlot assay kit (Cat \# 170-6460) following the manufacturer's instructions. An ELISA kit (Agdia Cat \# 730000480) was used to monitor nptII expression in the tobacco transformants. Two dilutions of protein samples were monitored with duplicate wells per dilution. The ELISA was performed following the protocol outlined by the manufacturer.

Amino acid composition

Free amino acid composition of tobacco tissue was ascertained from an initial $5 \mathrm{~g}$ (fresh weight) sample that was subsequently lyophilized. Amino acid analysis was conducted at the Experiment Station Chemical Laboratories at the University of Missouri-Columbia.

\section{Results and discussion}

A high percentage of the tobacco transformants derived from kanamycin selection with binary plasmid pPTN272 displayed developmental abnormalities (Figure 2). These included stunted growth, delay in flowering, leaf curling and slight chlorosis. Western blot data confirmed expression of ilva-466 in the assayed transgenic tobacco lines (Figure 3a). Leaf discs derived from line M5, along with wild-type explants, were evaluated in a regeneration study on tobacco regeneration medium supplemented with $4 \mathrm{mg} \mathrm{l}^{-1}, 6 \mathrm{mg} \mathrm{l}^{-}$ 1 , or $8 \mathrm{mg} \mathrm{l}^{-1}$ OMT. This study was composed of three replications (plates) per treatment with five explants per replication. The study was replicated twice. Leaf discs were scored for shoot initiation following 4 weeks of culture, with one subculture to fresh medium at the 2 -week time period. Wildtype leaf discs were substantially impacted in differentiation at all three OMT levels while explants derived from transgenic line M5 displayed a relatively high regeneration frequency on medium supplemented with OMT up to $8 \mathrm{mg} \mathrm{l}^{-1}$ (Table 1). These data suggested that expression of the ilvA466 imparts tolerance to OMT.

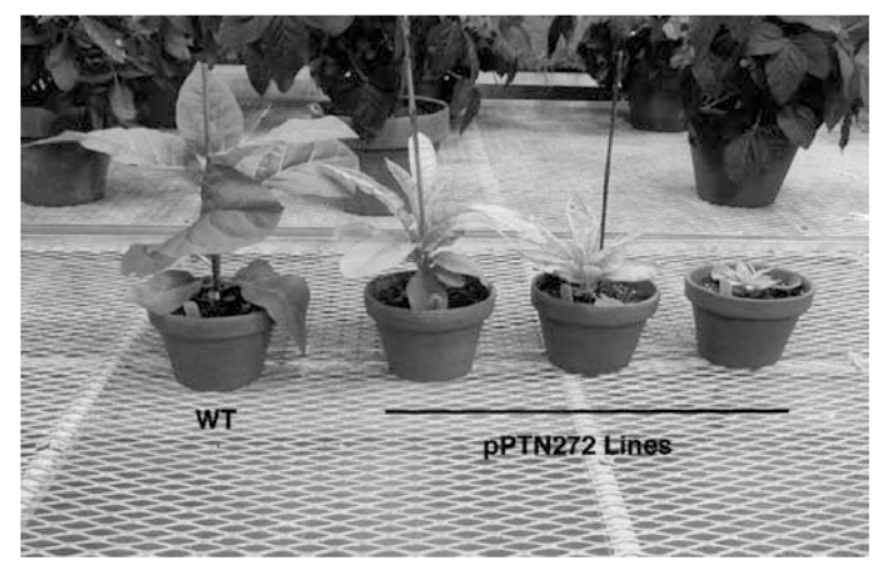

Figure 2 Mutant phenotype observed in tobacco (Nicotiana tabacum) transformants derived from binary vector pPTN272. Left Wild-type plant, right three transgenic lines derived from pPTN272. 


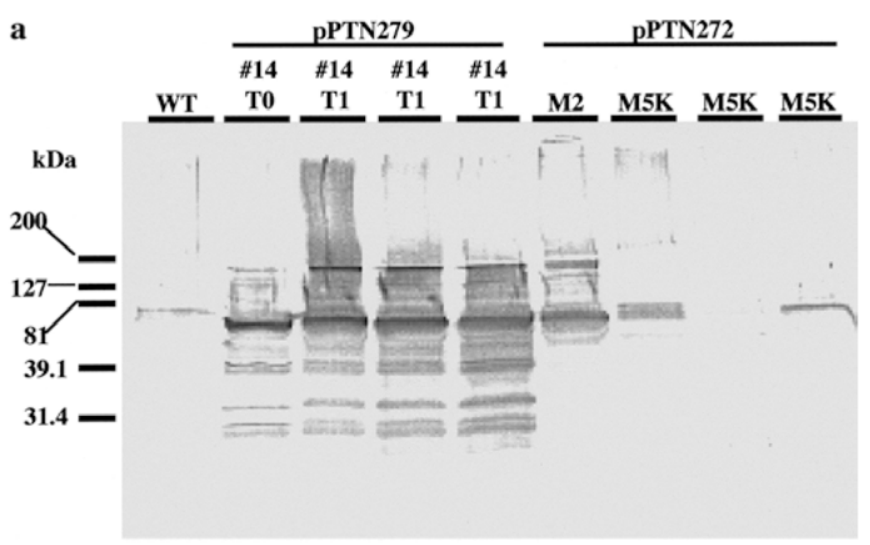

b pPTN279 Primary Transformants

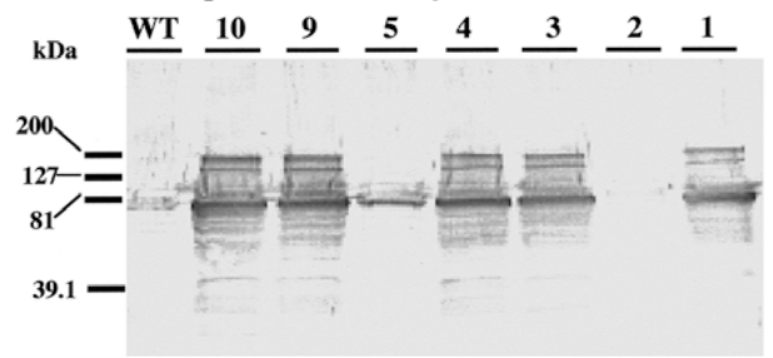

Figure 3 Western blot analysis on transgenic tobacco lines. a) Lanes (from left to right): 1, wild-type tobacco line; 2-5, parental line 14 (pPTN279) and three $\mathrm{T}_{1}$ individuals; 6 , $\mathrm{M} 2$ line $\left(\mathrm{T}_{0}\right)$; 7-9, three $\mathrm{T}_{1}$ progeny derived from line M5 (pPTN272). b) Lanes (from left to right): 1, wild-type tobacco line; 2-8, seven independent $\left(\mathrm{T}_{0}\right)$ transformants derived from binary vector pPTN279.

Table 1 Regeneration efficiency of transgenic tobacco (Nicotiana tabacum) expressing ilvA-466 under OMT selection pressure. $W T=$ Wild type

\begin{tabular}{|c|c|c|c|c|}
\hline $\begin{array}{l}\text { OMT level } \\
\left(\mathrm{mg} \mathrm{l}^{-1}\right)\end{array}$ & $\begin{array}{l}\text { Source of } \\
\text { explant }\end{array}$ & $\begin{array}{l}\text { Total No. } \\
\text { explants }^{\text {a }}\end{array}$ & $\begin{array}{l}\text { Total No. } \\
\text { regenerated }\end{array}$ & $\begin{array}{l}\text { Regeneration } \\
\text { efficiency }(\%)^{c}\end{array}$ \\
\hline 4.0 & WT & 30 & 10 & 30.0 \\
\hline 6.0 & WT & 30 & 1 & 3.0 \\
\hline 8.0 & WT & 30 & 0 & 0.0 \\
\hline 4.0 & ilva-466 Pos. & 24 & 24 & 100.0 \\
\hline 6.0 & ilva-466 Pos. & 23 & 19 & 83.0 \\
\hline 8.0 & ilva-466 Pos. & 19 & 13 & 68.0 \\
\hline
\end{tabular}

${ }^{a}$ Number of leaf discs put into culture across the respective OMT levels

${ }^{b}$ Total number of leaf discs with differentiated shoots following 4 weeks of culture

${ }^{\mathrm{c}}$ Percentage of leaf discs with differentiated shoots per treatment

Due to the high percentage of tobacco lines displaying a mutant phenotype in transformants expressing ilvA-466, we chose to focus our efforts on the wild-type ilvA gene as a direct selectable marker gene in tobacco transformation. Leaf discs were inoculated with C58C1 (pMP90) transconjugants carrying either pPTN279 or pPTN140 (Zhang et al. 1999). The latter binary vector harbors bar and $\beta$-glucuronidase (GUS) cassettes and served as a negative control in the transformation experiments. Tobacco leaf discs were inoculated and co-cultured for 3 days. Following the co-cul- tivation period the explants were transferred to regeneration medium supplemented with OMT levels ranging from $1.5 \mathrm{mg} \mathrm{l}^{-1}$ up to $12 \mathrm{mg} \mathrm{l}^{-1}$. The tissue was transferred to fresh medium every 2 weeks. The explants were scored at the 4-week time period for shoot differentiation. Following 8 weeks of culture, elongated shoots derived from OMT selection were transferred to rooting medium supplemented with OMT levels equivalent to that implemented during the differentiation stage or $6 \mathrm{mg} \mathrm{l}^{-1}$. A summary of the data derived from these experiments is provided in Table 2. Noninoculated leaf discs were severely impaired in regeneration efficiency at $4 \mathrm{mg} \mathrm{l}^{-1}$ (Table 1). However, a negative impact, on the inoculated control leaf discs, on differentiation due to OMT supplementation was not observed at levels up to $6 \mathrm{mg} \mathrm{l}^{-1}$. This differential tissue culture response observed from non-inoculated vs. inoculated leaf discs, is likely due to the interaction of the plant cell with A. tumefaciens. A similar modulation in culture response of soybean tissue inoculated with $A$. tumefaciens versus non-inoculated explants cultured on glufosinate-supplemented medium was previously reported (Zhang et al. 1999).

Tobacco leaf discs inoculated with the A. tumefaciens strain carrying pPTN279 were also negatively impacted in differentiation at levels comparable to the control vector; however, rooting efficiency on OMT-supplemented medium was enhanced with the pPTN279-derived shoots versus pPTN140 (control)-derived shoots, thus more plantlets were established in soil from the former (Table 2). Rooting efficiency on OMT-supplemented medium was the only parameter that was useful in identification of transgenic tobacco lines under the conditions used in this study. Non-transgenic shoots developed a poor rooting system, with one or two short thick primary roots emerging from the shoot base. Transgenic shoots, on the other hand, developed a vigorous rooting system (Figure 4). Based on screening of the primary lines for nptII expression, none of the shoots derived from pPTN279 inoculations with a poor rooting system established in soil was transformed. Transgenic lines with vigorous rooting systems were recovered from selection pressures of $1.5 \mathrm{mg} \mathrm{l}^{-1}, 3.0 \mathrm{mg} \mathrm{l}^{-1}$, and $8.0 \mathrm{mg} \mathrm{l}^{-1}$ OMT during the shoot differentiation step and rooted on either the same selection pressure used during differentiation or on $6 \mathrm{mg} \mathrm{l}^{-}$ ${ }^{1}$ OMT. The transformation frequencies, based on nptII positive per explant basis, observed were $3.7 \%, 0.7 \%$ and $7.4 \%$ for $1.5 \mathrm{mg} \mathrm{l}^{-1}, 3.0 \mathrm{mg} \mathrm{l}^{-1}$, and $8.0 \mathrm{mg} \mathrm{l}^{-1}$, respectively (Table 2). Tobacco transformation frequency with the pPTN279 binary vector employing kanamycin as the selection agent (150 $\mathrm{mg} \mathrm{l}^{-1}$ ) was greater than $80 \%$ (data not shown). Thus, the ability to identify tobacco transformants with the ilvA transgene as a selectable marker gene, coupled with OMT as the selection agent, was clearly differentiated at the rooting step under the conditions used in this study. However, the transformation frequency was substantially lower with the ilvA/OMT selection system than an nptII/kanamycin regime. 
Table 2 Summary of tobacco transformations with ilvA as the selectable marker gene. $N A=$ Not applicable

\begin{tabular}{|c|c|c|c|c|c|c|c|c|}
\hline $\begin{array}{l}\text { OMT level } \\
\left(\mathrm{mg} \mathrm{l}^{-1}\right)^{\mathrm{a}}\end{array}$ & Vector & $\begin{array}{l}\text { Total No. } \\
\text { explants }\end{array}$ & $\begin{array}{l}\text { Total No. } \\
\text { regenerated }\end{array}$ & $\begin{array}{c}\text { Rooting } \\
\text { OMT }\left(\mathrm{mg} \mathrm{l}^{-1}\right)^{\mathrm{d}}\end{array}$ & $\begin{array}{l}\text { Total No. } \\
\text { to rootinge }\end{array}$ & $\begin{array}{l}\text { Total No. } \\
\text { rooted }^{f}\end{array}$ & $\begin{array}{l}\text { Total No. } \\
\text { to soilg }\end{array}$ & $\begin{array}{l}\text { Transformation } \\
\text { efficiency }(\%)^{\mathrm{h}}\end{array}$ \\
\hline 1.5 & pPTN140 & 96 & 86 & 1.5 & 11 & 1 & 1 & NA \\
\hline 3.0 & pPTN140 & 71 & 56 & 3.0 & 10 & 6 & 2 & NA \\
\hline 8.0 & & & & 6.0 & 29 & 1 & 0 & NA \\
\hline 10.0 & pPTN140 & 152 & 1 & - & - & - & - & NA \\
\hline 12.0 & pPTN140 & 124 & 0 & - & - & - & - & NA \\
\hline \multirow[t]{2}{*}{8.0} & pPTN279 & 161 & 82 & 8.0 & 55 & 18 & 18 & $6.2(10)$ \\
\hline & & & & 6.0 & 16 & 5 & 5 & $1.2(2)$ \\
\hline 10.0 & pPTN279 & 142 & 0 & - & - & - & - & NA \\
\hline 12.0 & pPTN279 & 117 & 0 & - & - & - & - & NA \\
\hline
\end{tabular}

a OMT supplement in culture

${ }^{\mathrm{b}}$ Number of leaf discs put into culture across the respective treatments

${ }^{\mathrm{c}}$ Total number of leaf discs with differentiated shoots following 4 weeks of culture

${ }^{\mathrm{d}}$ OMT level to which elongated shoots were subjected during the rooting step

${ }^{\mathrm{e}}$ Number of shoots subjected to rooting per OMT level

${ }^{\mathrm{f}}$ Number of shoots with established roots

${ }^{\mathrm{g}}$ Number of rooted shoots that were established in soil

${ }^{\mathrm{h}}$ Percentage of plants on a per-explant basis that were nptII-positive based on ELISA. The number in parenthesis indicates the total number of plants that were nptII-positive

A subset of the transgenic lines recovered carrying the wild-type ilvA gene (pPTN279) also displayed a mutant phenotype similar to that observed in the ilvA-466 (pPTN272) transgenic lines. Western blot data confirmed the expression of the ilvA gene in these lines (Figure 3b) as well as stability of expression in the $\mathrm{T}_{1}$ generation (Figure $3 \mathrm{a}$ ). The phenotype was correlated with level of ilvA expression in the pPTN279 transgenic lines. However, no correlation with expression level and phenotype was observed with respect to the ilvA-466 (pPTN272) transgenic lines.

$\mathrm{T}_{1}$ seed collected from two pPTN279 transgenic lines designated 12 and 14, representing low- and high-ilvA-expressing lines, respectively, were sown on germination medium supplemented with $0 \mathrm{mg} \mathrm{l}^{-1}, 4 \mathrm{mg} \mathrm{l}^{-1}$, or $8 \mathrm{mg} \mathrm{l}^{-1}$ OMT along with wild-type tobacco seed. Germination medium was composed of MS salts (Murashige and Skoog 1962), Gamborg's vitamins (Gamborg et al. 1968) and 2\% sucrose. Following 3 weeks of germination, a clear dif- ference in seedling development was observed among the lines screened (Figure 5). Seeds from the wild type and the low-expressing line 12 germinated with minimal further development (Figure 5a, b). On the other hand, seeds from the high-expressing line 14 developed similar to the $0 \mathrm{mg}$ $\mathrm{l}^{-1}$ plate on OMT levels up to $8 \mathrm{mg}^{-1}$ (Figure $5 \mathrm{c}$ ).

The basis for tolerance to OMT, imparted to tobacco lines expressing either ilvA or ilvA-466, is the enhanced free intracellular Ile levels overriding the translational competitiveness of OMT. To verify this assumption, a subset of the tobacco lines was assayed for free amino acid content in leaf tissue at two stages, seedling and pre-flowering. High- and low-expressing ilvA (pPTN279) lines, 14 and 12 respectively, and one ilvA-466 line, M5, were assayed for free amino acid content along with wild-type tissue at similar developmental stages. The data revealed substantial enhancement of free Ile content in leaf tissue at the pre-flowering stage in the high-expressing ilvA line14 and ilvA-466 line M5 (Table 3), while the levels of no other amino acids
Figure 4 Rooting of tobacco shoots derived from OMT selection. a) Rooting ( $8 \mathrm{mg}^{-1}$ OMT) of tobacco shoots derived from pPTN279 inoculations. b) Rooting ( $8 \mathrm{mg} \mathrm{l}^{-1}$ OMT) of tobacco shoots derived from pPTN140 (control) inoculations.
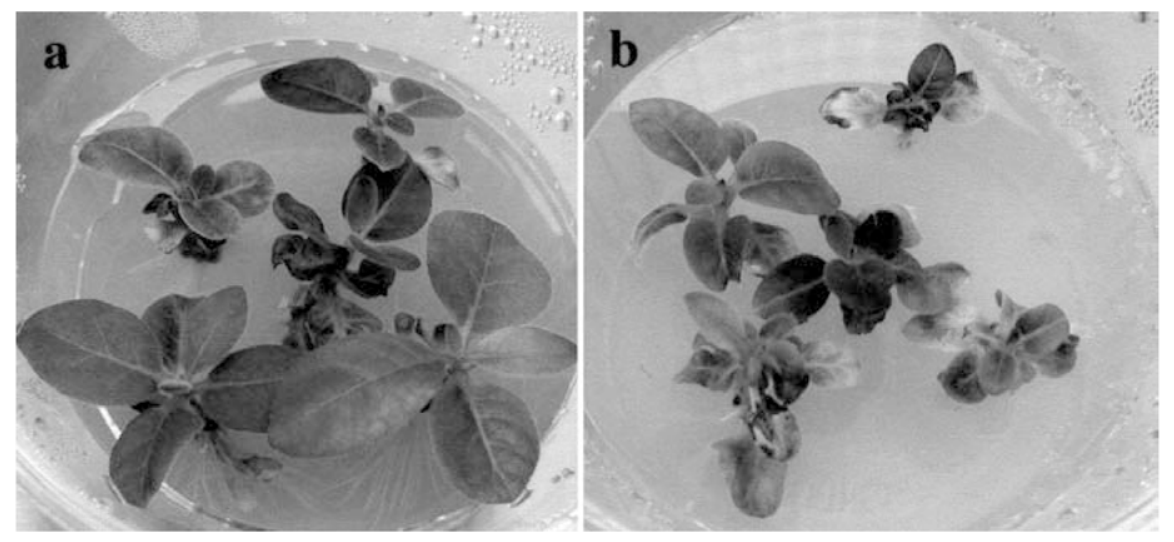


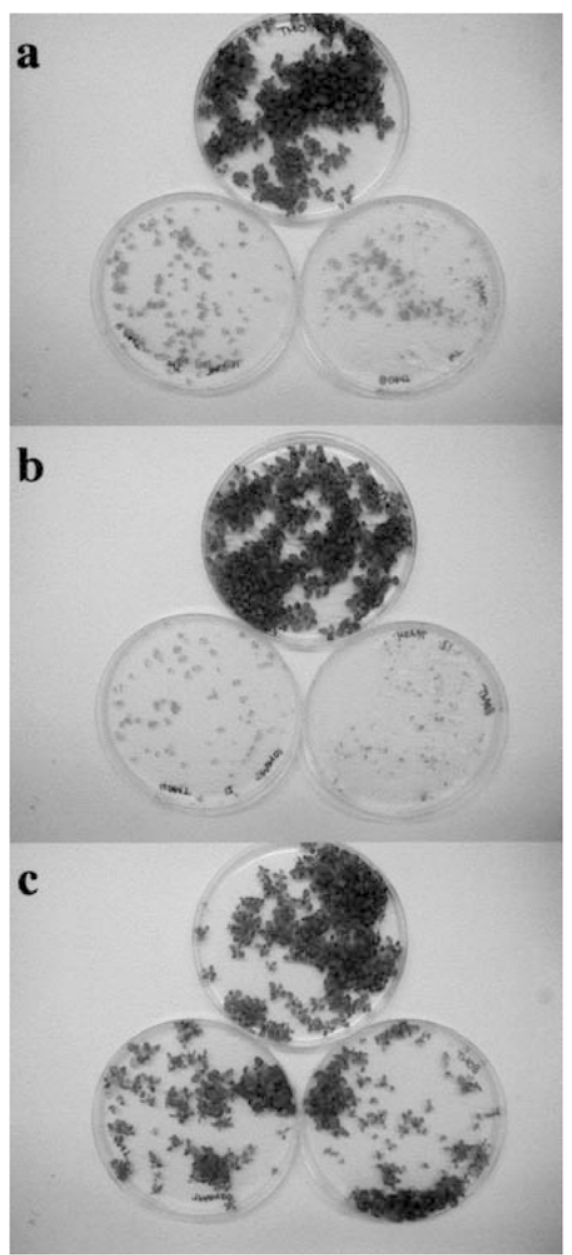

Figure 5 Seedling germination screen on transgenic tobacco lines. a) Wildtype tobacco seedlings. b) Line 12 (pPTN279)-derived seedlings c) Line 14 (pPTN279)-derived seedlings. In each panel: top plate $0 \mathrm{mg} \mathrm{l}^{-1}$ OMT, lower right plate $8 \mathrm{mg} \mathrm{l}^{-1}$ OMT, lower left plate $4 \mathrm{mg} \mathrm{l}^{-1}$ OMT.

monitored were affected (Table 3). Intracellular Ile content was correlated with transgene expression (Figure 6, Table 3). Elevated free Ile content was also observed in seedling tissue; however, transgene expression was not monitored at this stage, so no correlation could be made between

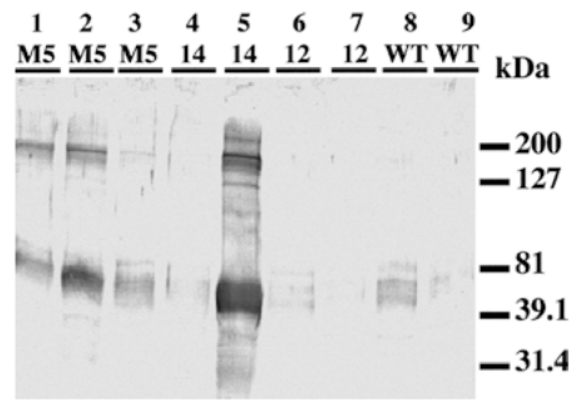

Figure 6 Western blot analysis on transgenic tobacco lines for TD expression. Lanes: $1-3 \mathrm{~T}_{1}$ individuals derived from line M5 (pPTN272); 4-5 $\mathrm{T}_{1}$ individuals derived from line 14 (pPTN279); 6-7 $\mathrm{T}_{1}$ individuals derived from line 12 (pPTN279); 8-9 wild-type tobacco.

expression and Ile content (data not shown).

Perturbing the carbon flux down-stream in the metabolic pathway of the aspartate-family biosynthetic pathway by expressing a deregulated TD or wild-type TD can significantly enhance intracellular Ile concentrations in planta. Slater et al. (1999) demonstrated that expression of ilvA enhanced free Ile in transgenic Arabidopsis by 5-fold. We observed a substantial enhancement of free Ile levels in cells of transgenic tobacco expressing either ilvA or ilvA-466 (Figure 6, Table 3). Progeny derived from ilvA line 14, corresponding to high TD expression, were able to develop normally on OMT-supplemented germination plates, while those derived from the wild type or the low-expressing line 12, which did not possess elevated intracellular levels of Ile, were substantially impaired in development (Figure 5).

In Arabidopsis, the omr1 allele of TD imparts tolerance towards OMT during seed germination, in agreement with what was observed here in tobacco transformants expressing high levels of ilvA. Moreover, leaf discs derived from transgenic tobacco expressing the ilvA-466 transgene were capable of enhanced regeneration potential compared to wild-type tobacco leaf discs on medium supplemented with OMT (Table 1), again reflecting ability of the E. coli TD to impart OMT tolerance in tobacco by modulating intracellu-

Table 3 Free amino acid levels within characterized tobacco lines. $N D=$ Not determined, $W T=$ wild type

\begin{tabular}{|c|c|c|c|c|c|c|c|c|c|c|c|c|c|c|c|}
\hline Lane\#/Line & \multicolumn{15}{|c|}{ Amino acid contents of individual plants ( $\mathrm{nmol} \mathrm{g}^{-1} \mathrm{FW}$ ) } \\
\hline $1 / \mathrm{M}^{\mathrm{b}}$ & 504 & 270 & 1,020 & 1,418 & 270 & 96 & 2,014 & 179 & 153 & 164 & 272 & 885 & 1,045 & 76 & 100 \\
\hline 3/M5 & ND & ND & ND & ND & ND & ND & ND & ND & ND & ND & ND & ND & ND & ND & ND \\
\hline $4 / 14$ & 516 & 147 & 1,358 & 1,047 & 142 & 62 & 65 & 97 & 73 & 121 & 168 & 946 & 1,590 & 41 & 137 \\
\hline $5 / 14^{\mathrm{b}}$ & 384 & 546 & 1,093 & 1,825 & 171 & 358 & 4,085 & 163 & 380 & 179 & 200 & 671 & 1,895 & 141 & 155 \\
\hline $7 / 12$ & 540 & 128 & 1,246 & 974 & 156 & 110 & 146 & 293 & 285 & 222 & 174 & 906 & 1,194 & 76 & 219 \\
\hline 8/WT & 480 & 116 & 1,157 & 974 & 128 & 89 & 130 & 277 & 204 & 86 & 168 & 1,099 & 1,114 & 70 & 191 \\
\hline 9/WT & 552 & 153 & 1,310 & 974 & 171 & 117 & 146 & 334 & 248 & 86 & 187 & 1,140 & 1,329 & 88 & 219 \\
\hline
\end{tabular}

${ }^{a}$ Lane designation in Figure 6 and the corresponding transgenic tobacco line

bPlant displayed the aberrant phenotype 
lar levels of Ile (Table 3). When ilvA was evaluated as a direct selectable marker gene, similar regeneration frequencies were observed across the OMT regimes tested in the control inoculations (pPTN140) and those with A. tumefaciens transconjugant carrying pPTN279 (Table 2). As mentioned above, in vitro differentiation of tobacco leaf discs directly cultured on regeneration medium supplemented with OMT was severely impacted at the $4 \mathrm{mg}^{-1}$ level (Table 1), while explants inoculated with the control $A$. tumefaciens transconjugant (pPTN140) were able to initiate shoot differentiation at levels up to $8 \mathrm{mg}^{-1}$ (Table 2). This difference is likely related to the bacterial interaction with the plant cells and highlights the importance of implementing inoculation controls when evaluating or optimizing selection agent regimes for plant genetic engineering studies.

Although tobacco explants inoculated with the pPTN279 transconjugant displayed similar in vitro differentiation rates under OMT selection pressures (Table 2), the shoots derived from the these inoculations rooted more efficiently, which is reflected in the increase in number of shoots established in soil. The transformation frequencies for the pPTN279 lines were based on a number of ELISA (nptII)positive lines established in soil on a per-explant basis. One possible explanation for the enhanced rooting efficiency observed in the pPTN279-derived shoots as compared to the pPTN140 (control) shoots, with the relatively high escape rate realized in the pPTN279 shoots rooted on OMT, is that a majority of the derived shoots were chimeric. If this were the case, it would suggest that the OMT selection pressures used during rooting were insufficient to prevent chimeric shoots from establishing a vigorous root system. If this assumption were correct, an ELISA screen would not be the most reliable assay to identify a chimeric primary plant. Regardless, even if $100 \%$ of the derived shoots obtained from the pPTN279 inoculations were chimeric, the transformation frequencies observed with ilvA under the selection regimes tested would still be substantially lower than that obtained with nptII coupled with $150 \mathrm{mg} / \mathrm{l}$ selection pressure.

The consistent observation with both ilvA and the partially Ile deregulated TD version, ilvA-466, was the occurrence of developmental abnormalities (Figure 2) in a subset of the derived transformants. Slater et al. (1999) reported lethality in both Arabidopsis and Brassica in a fully deregulated version of ilvA designated ilvA-219, and some negative impacts with ilvA-466 only in Arabidopsis, while seed-specific expression of ilvA-466 in Brassica was tolerated with no apparent developmental aberrations. The wild-type ilvA on the other hand, showed no phenotypic abnormalities in either constitutive expression or in a seed-specific fashion, in Arabidopsis or Brassica, respectively. It was speculated that as a consequence of enhanced TD activity, a build up of intracellular ammonia could be manifested, which in turn could induce cell death (Slater et al. 1999). If this is true it suggests a differential tolerance towards intracellular con- centrations of ammonia among the plant species, with tobacco being more sensitive than Arabidopsis. However, in the studies outlined herein, we used a modified 35S CaMV promoter coupled with both transcriptional and translational enhancer elements shown to significantly increase transgene expression over the core 35S CaMV promoter (Mitsuhara et al. 1996). Thus, the lack of growth abnormalities in ilvA transgenic Arabidopsis reported by Slater et al. (1999) and the observation of off-types in ilvA transgenic tobacco described here, may be merely reflective of elevated ilvA expression in the latter, and not due to differential toxicity of intracellular ammonia concentrations.

We have demonstrated that expression of $E$. coli TD can impart tolerance towards OMT and that the wild-type ilvA can be used to identify transgenic tobacco lines, albeit relatively inefficiently, thus, confirming the hypothesis put forth by Mourad and King (1995). However, further optimizations will be required to allow this selection system to be of any potential value in plant genetic engineering studies. Moreover, modulating the carbon flux through the aspartate-family biosynthetic pathway may impact intracellular levels of other aspartate-derived amino acids due to the intertwined regulation of synthesis of the respective amino acids within the pathway (Amir et al. 2002). The amino acid profile of the transgenic tobacco lines characterized herein only displayed major differences in free Ile levels (Table 3 ) due to the expression of the E. coli TD gene, which correlated with a negative phenotype. However, to detect minor fluctuations of other amino acid levels, which may be manifested as a result of the expression of the $E$. coli TD, may require large sample sizes, due to high inherent variation. Therefore, if the E. coli TD gene can be optimized for use in a selection scheme, given the potential for negative developmental abnormalities being generated (Figure 2) and/or alteration of intracellular amino acid profile as a consequence of constitutive perturbation of the aspartate family biosynthetic pathway, additional measures, such as recombination approaches (Dale and Ow 1991; Zuo et al. 2001) or the simultaneous delivery of two T-DNA elements (Komari et al. 1996; Xing et al. 2000), would undoubtedly need to be taken for the subsequent removal of the TD transgene from the genome.

\section{Acknowledgements}

The ilvaA, ilva-466 genes and TD antibodies were kindly provided by Monsanto Company. Gratitude is extended to Tim Mitsky for thoughtful discussions on this project. Pioneer Hi-Bred provided fellowship support for A. Ebmeier. This project was partially supported from monies from the Nebraska Research Initiative and the University of Nebraska-Lincoln's Center for Biotechnology. This paper is a contribution of the University of Nebraska Agricultural Research Division. This is Journal Series No. 14157. 


\section{References}

Amir R, Hacham Y, Galili G (2002) Cystathionine $\gamma$-synthase and threonine synthase operate in concert to regulate carbon flow towards methionine in plants. Trends Plant Sci 7:153-156

Arruda P, Bright SW, Kueh JSH, Lea PJ, Rognes SE (1984) Regulation of aspartate kinase isoenzymes in barley mutants resistant to lysine plus threonine. Plant Physiol 76:442-446

Barry G, Kishore G, Padgette S, Taylor M, Kolacz K, Weldon M, Re D, Eichholtz D, Fincher K, Hallas L (1992) Inhibitors of amino acid biosynthesis: strategies for imparting glyphosate tolerance to crop plants. In: Singh BK et al (eds) Biosynthesis and molecular regulation of amino acids in plants. American Society of Plant Physiologists, Rockville, MD, pp 139-145

Bryan JK (1980) Synthesis of the aspartate family and branched-chain amino acids. In: Miflin BJ (ed) The biochemistry of plants, vol 5. Academic Press, New York, pp 403-452

Dale EC, Ow DW (1991) Gene transfer with subsequent removal of the selection gene from the host genome. Proc Natl Acad Sci USA 88:10588-10562

De Block M, De Brouwer D, Tenning P (1987) Transformation of Brassica napus and Brassica oleracea using Agrobacterium tumefaciens and the expression of the bar and neo genes in the transgenic plants. Plant Physiol 91:694-701

Ditta G, Stanfield S, Corbin D, Helinski D (1980) Broad host range DNA cloning system for gram-negative bacteria: construction of a gene bank of Rhizobium meliloti. Proc Natl Acad Sci USA 77:7347-7351

Eichholtz D, Rogers S, Horsch R, Klee H, Hayford M, Hoffmann N, Bradford S, Fink C, Flick J, O'Connell K, Fraley R (1987) Expression of mouse dihydrofolate reductase gene confers methotrexate resistance in transgenic petunia plants. Somatic Cell Mol Genet 13:67-76

Fraley RT, Rodgers SG, Horsch RB, Sanders PR, Flick JS, Adams SP, Bittner ML, Brand LA, Fink CL, Fry JS, Galluppi GR, Goldberg SB, Hoffmann NL, Woo SC (1983) Expression of bacterial genes in plant cells. Proc Natl Acad Sci USA 80:4803-4807

Gamborg OL, Miller RA, Ojima K (1968) Nutrient requirements of suspension cultures of soybean root cells. Exp Cell Res 50:152-158

Hajdukiewicz P, Svab Z, Maliga P (1994) The small, versatile pPZP family of Agrobacterium binary vectors for plant transformation. Plant Mol Biol 25:989-994

Horsch R, Fry J, Hoffman N, Eichholtz D, Rogers S, Fraley R (1985) A simple and general method for transferring genes into plants. Science 227:1229-1231

Joersbo M, Petersen SG, Okkels FT (1999) Parameters interacting with mannose selection employed for the production of transgenic sugar beet. Physiol Plant 105:109-115

Komari T, Hiei Y, Saito Y, Murai N, Kumashiro T (1996) Vectors carrying two separate T-DNAs for co-transformation of higher plants mediated by Agrobacterium tumefaciens and segregation of transformants free from selection markers. Plant J 10:165-174

Koncz C, Schell J (1986) The promoter of $\mathrm{T}_{\mathrm{L}}$-DNA gene 5 controls the tissuespecific expression of chimaeric genes carried by a novel type of Agrobacterium binary vector. Mol Gen Genet 204:383-396
Negrotto D, Jolley M, Beer S, Wenck AR, Hansen G (2000) The use of phosphomannose-isomerase as a selectable marker to recover transgenic maize plants (Zea mays L) via Agrobacterium transformation. Plant Cell Rep 19:798-803

Maier-Greiner UH, Klaus CBA, Estermaier LM, Hartmann GR (1991) Herbicide resistance in transgenic plants through degradation of the phytotoxin to urea. Angew Chem Int Ed Engl 30:1314-1315

Miao S, Duncan DR, Widholm JM (1988) Selection of regenerable maize callus cultures resistant to 5-methyl-DL-tryptophan, S-(2-aminoethyl)L-cysteine and high levels of L-lysine plus L-threonine. Plant Cell Tissue Org Cult 14:3-14

Mitsuhara I, Ugaki M, Hirochika H, Ohshima M, Murakami T, Gotoh Y, Katayose Y, Nakamura S, Honkura R, Nishimiya S, Ueno K, Mochizuki A, Tanimoto H, Tsugawa H, Otsuki Y, Ohashi Y (1996) Efficient promoter cassettes for enhanced expression of foreign genes in dicotyledonous and monocotyledonous plants. Plant Cell Physiol 37:49-59

Mourad GR, King J (1995) L-O-Methylthreonine-resistant mutant of Arabidopsis defective in isoleucine feedback regulation. Plant Physiol 107:43-52

Murashige T, Skoog F (1962) A revised medium for rapid growth and bioassays with tobacco tissue cultures. Physiol Plant 15:473-497

Perl A, Galili S, Shaul O, Ben-Tzvi I, Galili G (1993) Bacterial dihydrodipicolinate synthase and desensitized aspartate kinase: two novel selectable markers for plant transformation. Bio/Technology 11:715-718

Rabinovitz M, Olson ME, Greenberg DM (1955) Steric relationship between threonine and isoleucine as indicated by an antimetabolite study. J Am Chem Soc 77:3109-3111

Rognes SE, Bright SWJ, Miflin BJ (1983) Feedback-insensitive aspartate kinase isoenzymes in barley mutants resistant to lysine plus threonine. Planta 157:32-38

Slater S, Mitsky TA, Houmiel KL, Hao M, Reiser SE, Taylor NB, Tran M, Valentin HE, Rodriguez DJ, Stone DA, Padgette SR, Kishore G, Gruys KJ (1999) Metabolic engineering of Arabidopsis and Brassica for poly(3hydroxybutyrate-co-3-hydroxyvalerate) copolymer production. Nature Biotechnol 17:1011-1016

Szamosi IT, Shaner DL, Singh BK (1994) Inhibition of threonine dehydratase is herbicidal. Plant Physiol 106:1257-1260

Thompson CJ, Movva NR, Tizzard R, Crameri R, Davies JE, Lauwereys M, Botterman J (1987) Characterization of the herbicide-resistance gene bar from Streptomyces hygroscopicus. EMBO 6:2519-2523

Waldron C, Murphy EB, Roberts JL, Gustafson SG, Armour SL, Malcolm SK (1985) Resistance to hygromycin B a new marker for plant transformation studies. Plant Mol Biol 5:103-108

Weeks JT, Koshiyama KY, Maier-Greiner U, Schäeffner T, Anderson OD (2000) Wheat transformation using cyanamide as a new selective agent. Crop Sci 40:1749-1754

Xing A, Zhang Z, Sato S, Staswick P, Clemente T (2000) The use of the two T-DNA binary system to derive marker-free transgenic soybeans. In Vitro Cell Dev Biol Plant 36:456-463

Zhang Z, Xing A, Staswick P, Clemente TE (1999) The use of glufosinate as a selective agent in Agrobacterium-mediated transformation of soybean. Plant Cell Tissue Org Cult 56:37-46

Zuo J, Niu QW, Møller SG, Chua N-H (2001) Chemical-regulated, site-specific DNA excision in transgenic plants. Nat Biotechnol 19:157-161 